Published in final edited form as:

Gen Hosp Psychiatry. 2015 ; 37(4): 277-282. doi:10.1016/j.genhosppsych.2015.03.021.

\title{
Psychiatric Comorbidity in Depressed HIV-infected Individuals: Common and Clinically Consequential
}

\author{
Bradley N. Gaynes, MD, MPH, \\ Department of Psychiatry, University of North Carolina School of Medicine, Chapel Hill, North \\ Carolina \\ Julie O'Donnell, MPH, \\ Department of Epidemiology, University of North Carolina at Chapel Hill, Chapel Hill, North \\ Carolina.jkodonne@email.unc.edu \\ Elise Nelson, MSc, \\ Center for Health Policy and Inequalities Research, Duke University, Durham, North Carolina \\ elise.nelson@duke.edu
}

\section{Amy Heine, MSN, FNP-BC,}

Division of Infectious Diseases, Department of Medicine, University of North Carolina at Chapel Hill, Chapel Hill, North Carolina amy_heine@med.unc.edu

\author{
Anne Zinski, PhD, \\ Division of Infectious Diseases, University of Alabama at Birmingham School of Medicine, \\ Birmingham, Alabama azinski@uab.edu
}

\author{
Malaika Edwards, MS, \\ Infectious Diseases Clinic, Institute for Global Health and Infectious Diseases, University of North \\ Carolina at Chapel Hill, Chapel Hill, North Carolina malaika_edwards@med.unc.edu

\section{Teena McGuinness, PhD, CRNP, FAAN,} \\ School of Nursing, University of Alabama at Birmingham, Birmingham, Alabama tmcg@uab.edu \\ Modi A. Riddhi, MBBS, MPH, \\ Department of Medicine, University of Alabama at Birmingham, Birmingham, Alabama \\ rmodi@uab.edu
}

\author{
Charita Montgomery, BS, and \\ Infectious Diseases Clinic, Institute for Global Health and Infectious Diseases, University of North \\ Carolina at Chapel Hill, Chapel Hill, North Carolina charita_montgomery@med.unc.edu
}

\footnotetext{
(C) 2015 Published by Elsevier Inc.

Corresponding author: Dr. Bradley N. Gaynes, MD, MPH, Professor of Psychiatry and Associate Chair for Research Training and Education, CB \#7160, Department of Psychiatry, Suite 304, Room J, MacNider Building, University of North Carolina School of Medicine, Chapel Hill, NC 27599-7160; Bradley_gaynes@med.unc.edu, bgaynes@med.unc.edu, tel: (919) 445-0214, fax: (919) 445-0234.

Publisher's Disclaimer: This is a PDF file of an unedited manuscript that has been accepted for publication. As a service to our customers we are providing this early version of the manuscript. The manuscript will undergo copyediting, typesetting, and review of the resulting proof before it is published in its final citable form. Please note that during the production process errors may be discovered which could affect the content, and all legal disclaimers that apply to the journal pertain.
} 
Brian W Pence, PhD, MPH

Department of Epidemiology, University of North Carolina at Chapel Hill, Chapel Hill, North

Carolina bpence@unc.edu

\section{Abstract}

Objective-To report on the prevalence of psychiatric comorbidity and its association with illness severity in depressed HIV patients.

Methods-As part of a multi-site randomized controlled trial of depression treatment for HIV patients, 304 participants meeting criteria for current Major Depressive Disorder (MDD) were assessed for other mood, anxiety and substance use disorders with the Mini-International Neuropsychiatric Interview, a structured psychiatric diagnostic interview. We also assessed baseline adherence, risk, and health measures.

Results-Complicated depressive illness was common. Only $18 \%$ of participants experienced MDD with no comorbid psychiatric diagnoses; $49 \%$ had comorbid dysthymia, $62 \%$ had $\geq 1$ comorbid anxiety disorder, and $28 \%$ had a comorbid substance use disorder. Self-reported antiretroviral adherence did not differ by the presence of psychiatric comorbidity. However, psychiatric comorbidity was associated with worse physical health and functioning: compared to those with MDD alone, individuals with $\geq 1$ comorbidity reported more HIV symptoms (5.1 vs. 4.1, p-value $=0.01)$, and worse mental health-related quality of life on the SF-12 (29 vs. 35, $\mathrm{p}<0.01)$.

Conclusion-For HIV patients with MDD, chronic depression and psychiatric comorbidity are strikingly common, and this complexity is associated with greater HIV disease severity and worse quality of life. Appreciating this comorbidity can help clinicians better target those at risk of harder-to-treat HIV disease, and underscores the challenge of treating depression in this population.

\section{Keywords}

depression; psychiatric comorbidity; quality of life

\subsection{INTRODUCTION}

Twenty to thirty percent of HIV-infected patients have depression or depressive symptoms, and these states have been associated with decreased access to antiretroviral therapy (ART) [1-4], decreased likelihood of initiation of and retention in HIV care,[5, 6] poor antiretroviral adherence,[7] worse psychiatric outcomes,[8] and worse medical outcomes, including lower likelihood of virologic suppression, faster HIV disease progression, and higher mortality rates. $[9,10]$ HIV care providers and researchers have argued that increased access to effective depression treatment would lead to substantial improvements in HIV clinical outcomes for affected individuals, $[8,11]$ although current evidence is somewhat mixed on this point.[12-18]

A key consideration in determining whether improved depression care can lead to improved HIV outcomes in HIV-infected individuals with Major Depressive Disorder (MDD) is how 
comorbid psychiatric illness might confound this relationship. Indeed, few studies have thoroughly considered the role of psychiatric comorbidity, i.e., the co-occurrence of other psychiatric disorders with depression, in explaining the observed association between depressive symptoms and adverse HIV outcomes. For psychiatric illness in general, and MDD in particular, having more than one concurrent psychiatric diagnosis is common.[19] This psychiatric comorbidity is strongly related to both greater psychiatric severity [20] and worse psychiatric outcomes (including greater fatigue and functional impairment[21] and higher rates of suicide attempts[22]). In addition, psychiatric comorbidity is associated with greater medical symptomatology[23] and worse medical outcomes.[24] Finally, MDD that is comorbid with dysthymic, anxiety, or substance use disorders is likely to be more difficult to treat, which might complicate efforts to reduce depressive severity and improve HIV outcomes through depression treatment interventions.

However, documentation of psychiatric comorbidity in HIV patients receiving treatment in limited. Indeed, while studies have reported on the heavy burden of psychiatric illness in HIV-infected populations, [25, 26] no prior study has specified psychiatric comorbidity in a sample of HIV-infected patients with a confirmed diagnosis of MDD, nor whether this comorbidity is associated with greater illness severity. In this paper, our team assesses the prevalence and correlates of psychiatric comorbidity among a population of HIV-infected patients with confirmed MDD who enrolled in a depression treatment study. We examine the extent to which depression treatment interventions for HIV-infected individuals needs to consider psychiatric comorbidity for maximal reach and effectiveness. Accordingly, our goals for this paper are 1) to describe the prevalence of comorbid psychiatric disorders in persons with MDD enrolling in a depression treatment study in a representative sample of HIV outpatients, and 2) to identify sociodemographic and clinical/behavioral features associated with the number and type of concurrent psychiatric conditions.

\subsection{MATERIALS AND METHODS}

\subsubsection{Study Design/setting}

SLAM DUNC was a randomized controlled effectiveness trial implemented at the infectious diseases clinics at 3 academic medical centers: Duke University (lead site; Clinic 2J), the University of North Carolina at Chapel Hill (UNC Infectious Diseases Clinic), and the University of Alabama at Birmingham (1917 Clinic).[27] It was designed to test whether evidence-based decision support for antidepressant management, when integrated into HIV care, would improve HIV medication adherence and clinical outcomes (ClinicalTrials.gov registry \# NCT01372605). Eligible and consenting participants were randomized to one of two conditions: Measurement-Based Care (MBC, hereafter referred to as "intervention") or enhanced treatment as usual (hereafter referred to as "usual care"). No advertisements for clinical trial participants were conducted; all potential participants were already patients in the respective clinics.

\subsubsection{Study population}

Patients seeking care at participating sites were eligible if they were HIV-infected, ages 18-65 years old, English-speaking, prescribed or about to start any FDA-approved 
antiretroviral medication, scored 10 or higher on the Patient Health Questionnaire-9 depression screener [28], and subsequently had a current major depressive disorder diagnosis confirmed by the Mini International Neuropsychiatric Interview (MINI), a commonly used short structured diagnostic interview with excellent reliability and good-tovery good convergent validity relative to other gold standards for a variety diagnoses. [29-31] Patients were excluded if they had a history or a current diagnosis of either a bipolar spectrum disorder $(n=34)$ or a psychotic disorder or psychotic symptoms $(n=19)$ as diagnosed by the MINI; were currently suicidal or had a substance use disorder requiring immediate inpatient treatment $(\mathrm{n}=1)$; or failed to respond to adequate trials of $\geq 2$ different antidepressants during the current depressive episode $(n=2)$. Written informed consent was obtained from each participant and all study activities were approved by the Institutional Review Boards at Duke University, the University of North Carolina at Chapel Hill, and the University of Alabama at Birmingham.

\subsubsection{Assessment of Psychiatric Comorbidity}

All diagnoses were based on DSM-IV-TR criteria.[32] At the time of enrollment, patients were evaluated for dysthymia (a chronic, low grade depressive illness now referred to as persistent depressive disorder in the DSM-V[33]), panic disorder, generalized anxiety disorder (GAD), posttraumatic stress disorder (PTSD), alcohol dependence/abuse, and substance dependence/abuse, using the relevant subsections of the MINI.

\subsubsection{Associated baseline variables of interest}

We collected standard sociodemographic measures as well as clinical and behavioral measures thought to be relevant to psychiatric comorbidities. Specifically, we assessed adherence, using a baseline self-report along a visual analog scale from 0-100\% of how much of the time the participant took all of the prescribed HIV/AIDS medicines over the prior month;[34] a self-report of 12 potential HIV-related symptoms over the prior 6 months (headaches; fever, sweats or chills; pain in the mouth; white patches in the mouth; painful rashes or sores; nausea or loss of appetite; eye trouble; sinus infection; numbness in hands or feet; persistent cough; diarrhea);[35] a self-report measure of sexual behaviors, including unprotected sex, over the prior 3 months; a measure of health-related quality of life using the Short Form 12 (SF-12),[36] which has a general population mean of 50 for physical and mental health subscores and for which higher scores indicate better quality of life; suicidality over the past week, as indicated on the Hamilton Rating Scale for Depression-17 item version (HRSD)[37]; detectable viral load (HIV RNA VL >48 copies/mL); and selfreport of hospitalization and emergency department use over the prior 3 months.

\subsubsection{Data Analysis}

Data are presented as means (standard deviations) or percentages. Chi-square tests, t-tests, and ANOVA were used to compare categorical and continuous characteristics and outcomes (a) between those with no vs. one or more comorbidities, and (b) between those with depressive disorders only (depression with or without dysthymia) vs. those with comorbid anxiety disorders (but no substance use) or vs. those with comorbid substance use disorders (with or without anxiety disorders). We used multiple linear and logistic regression to estimate the independent associations of dysthymic, anxiety, and substance use disorders 
with a range of behavioral and health outcomes, with all models adjusted for covariates determined to be important a priori (age, gender, and employment status). A p-value of $<0.05$ was considered statistically significant; a p-value between 0.05 and 0.10 was considered a trend. No adjustments of P-values for multiple comparisons were performed given the exploratory nature of this report.

\subsection{RESULTS}

\subsubsection{Sample description}

The SLAM-DUNC study enrolled 304 participants (Table 1). The mean age of those participating was 44 years, and $71 \%$ were male. The sample averaged 13 years of completed education. Sixty-two percent of those enrolled were black, $51 \%$ were single or never married, and $73 \%$ were unemployed. On average, participants had been diagnosed with HIV for 11 years.

Self-reported adherence to ART was high, with a mean self-reported adherence of $87 \%$. The mean number of reported HIV symptoms was 5.1. Both mental functioning (mean SF-12 Mental Health Composite Score $=30$ ) and physical functioning (mean SF-12 Physical Composite Score $=44$ ) suggested below average health-related quality of life. Thirty-three percent of participants had a detectable viral load ( $>48$ copies $/ \mathrm{mL})$, and $18 \%$ reported having had unprotected sex in the past 3 months.

\subsubsection{Prevalence of comorbid disorders}

All participants had complete comorbidity information. Complicated depressive illness was common. Most MDD (59\%) was recurrent (Table 1). Only 18\% (4\% single episode, $14 \%$ recurrent) were experiencing MDD with no comorbid psychiatric diagnoses (Figure 1). Chronic depression was common, with $49 \%$ of MDD patients having a concurrent dysthymic disorder (Table 2). Comorbid anxiety disorder was present in $62 \%$, most commonly GAD (48\%), followed by PTSD (22\%) and Panic Disorder (14\%). A comorbid substance use disorder existed in $28 \%$, with the prevalence of dependence on alcohol or drugs (15-16\%) being more common than abuse (3-5\%). Of all participants, $30 \%$ had one comorbid diagnosis besides MDD, 28\% had 2 concurrent diagnoses, and $25 \%$ had 3 or more comorbidities.

\subsubsection{Clinical and sociodemographic features associated with various degrees of comorbidity}

There was little difference in baseline sociodemographic variables between those with no comorbidities and those with 1 or more (Table 3). The comorbid group did not differ from the MDD alone group by age, sex, race, income level, time since diagnosis, or education. However those with any comorbidity were significantly more likely to be unemployed (76\% vs. $59 \%, \mathrm{p}=0.01$ ). Compared to those with only depression and/or dysthymia, the likelihood of unemployment was higher among those with anxiety disorders ( $79 \%$ vs. $62 \%, \mathrm{p}=0.01$ ) and showed a trend toward being higher among those with substance use disorders (75\% vs. $62 \%, \mathrm{p}=0.08)$. 
Comorbidity, in general, was associated with greater disease severity. Of note, this association was not observed in self-reported adherence or HIV viral load suppression at baseline, which did not vary between groups (Table 3). However, psychiatric comorbidity was associated with greater HIV symptom severity. Compared to those with MDD alone, the comorbid group reported more mean HIV symptoms (5.1 vs. 4.1, $\mathrm{p}=0.01$ ) and tended to report worse physical functioning on the SF-12 (43 vs. 47, p=0.08). Also, the comorbid group reported lower overall mental health functioning $(\mathrm{p}<0.01)$. Compared to those with depressive or dysthymic disorders alone, mental health functioning was lower among those with anxiety disorders (mean $=28$ vs. $33, \mathrm{p}<0.01$ ) but was not statistically significantly different among those with substance use disorders (31 vs. 33, $\mathrm{p}=0.14$ ).

Finally, we used multivariable regression models to assess whether there were independent associations between the specific types of psychiatric comorbidity and HIV behavioral and health outcomes (Table 4). Having a comorbid dysthymic disorder was significantly associated with worse mental functioning and nearly twice the likelihood of suicidality within the past week. Further, there was a trend towards a greater likelihood of an emergency department visit for this population $(\mathrm{p}<0.10)$. Having a comorbid anxiety disorder was significantly associated with a greater number of reported HIV symptoms and worse mental health functioning, but no clear association with increased suicidality or increased emergency department use. There was a trend towards worse physical functioning $(\mathrm{p}<0.10)$ for those with a comorbid anxiety disorder.

Substance use comorbid with depression was associated with a trend towards greater odds of having a detectable viral load and greater odds of unprotected sex in the previous 3 months $(\mathrm{p}<0.10)$

\subsection{DISCUSSION}

In the only study to date that provides a diagnostic assessment of psychiatric comorbidity in a sample of HIV patients with MDD receiving ART, we found that having a comorbid psychiatric illness is the norm. Nearly half of study participants had a comorbid dysthymic disorder, a chronic depressive illness distinct from MDD that is an independent risk factor for treatment-resistant depression.[38] Even when one excludes dysthymia, three quarters of depressed patients had a comorbid anxiety and/or substance use disorder. Thus, in this patient population of HIV-infected individuals selected as reasonable candidates for a depression treatment study, the prevalence of comorbid psychiatric disorders likely to complicate the depression treatment course was high.

Prior assessments of psychiatric comorbidity have been limited and primarily based on either retrospective chart reviews of diagnoses.[39] or by positive psychiatric screens (rather than diagnostic assessments),[40] which can overstate prevalence rates by as much as $16 \%$ in this population. [41, 42] One exception carefully assessed multiple psychiatric diagnoses using the Structured Clinical Interview for DSM-IV on a convenience sample of 66 patients who had screened positive for depression, but this study did not characterize psychiatric comorbidity in those specifically with MDD.[43] Further, their sample differed by including depressed patients with psychotic symptoms or bipolar spectrum illness, which our selection 
criteria excluded, and by assessing for dysthymia. Their findings showed MDD-only diagnosis in $4 \%$ of the screen positive sample, and they reported the same proportion (62\%) had anxiety comorbid with MDD. However, twice as many in their sample were diagnosed with comorbid anxiety, depressive, and substance use disorders (30\% vs. 14\% prevalence). Further, specific types of comorbidity differed. We identified $22 \%$ with comorbid PTSD, compared to $10 \%$ in their population of those with screen-positive depression. These differences are likely related to the dissimilar populations sampled, but underscore the complexity of comorbid psychiatric presentations in HIV clinical settings.

In our study, psychiatric comorbidity was associated with greater HIV disease severity and worse quality of life, reflected in greater HIV symptomatology and worse physical and mental health functioning. For example, those with comorbid dysthymia were nearly twice as likely to have suicidal thoughts in the past week, suggesting a greater need for more frequent and closer monitoring of psychological status. Having a comorbid substance use disorder was associated with nearly twice the likelihood of having a detectable viral load while on ART, suggesting a greater need for more frequent and closer monitoring of a patient's HIV treatment response. Having both comorbidities (12\% of our sample) might suggest the need to monitor both psychiatric and HIV clinical status more closely. In any case, the frequency and associated effects of these comorbidities suggest the need for more comprehensive treatment plans for patients presenting to the HIV clinic with MDD.

Our study has limitations. It is cross-sectional and so can only assess associations, not causal relationships. However, these results underscore the complexity of HIV-infected patients presenting with depression and identify psychiatric comorbidity as a potential key confounder of the association between depression and adverse HIV outcomes. Also, our findings apply only to those with MDD, and are not applicable to patients with psychotic or bipolar disorders. Such a focus, however, is likely more representative of patients whose mental health might be managed in an outpatient HIV clinic, as those with psychotic or bipolar spectrum presentations more often would be referred to a mental health professional. Finally, our study is exploratory in nature and a first step towards better understanding this comorbidity; larger studies are necessary to confirm these findings.

For HIV patients with major depression, psychiatric comorbidity and chronic depression are strikingly common rather than the exception, and this complexity is associated with greater HIV disease severity and worse prevention and treatment indicators. An appreciation of this comorbidity can help clinicians better target those at risk of harder-to-treat HIV disease, and it underscores the challenge of treating depression in this population.

\section{Acknowledgements}

This study was supported by grant R01MH086362 of the National Institute of Mental Health and the National Institute for Nursing Research, National Institutes of Health, Bethesda, MD, USA. Support was also provided by the Centers for AIDS Research at the University of North Carolina at Chapel Hill, Duke University, and the University of Alabama at Birmingham NIH-funded programs (P30- AI50410; P30-AI064518; and P30-AI027767). The content is solely the responsibility of the authors and does not necessarily represent the official views of the NIMH or the NIH. 


\section{ABBREVIATIONS}

\section{MDD \\ SLAM DUNC \\ Study}

MINI

GAD

HRSD

ANOVA

SF-12

PTSD
Major Depressive Disorder

Strategies to Link Antidepressant and Antiretroviral Management at Duke University, University of Alabama-Birmingham, Northern Outreach Clinic, and University of North Carolina-Chapel Hill Study

Mini International Neuropsychiatric Interview

Generalized Anxiety Disorder

Hamilton Rating Scale for Depression

Analysis of Variance

Short Form 12

Post-Traumatic Stress Disorder

\section{References}

1. Fairfield KM, et al. Delays in protease inhibitor use in clinical practice. J Gen Intern Med. 1999; 14(7):395-401. [PubMed: 10417596]

2. Tucker JS, et al. Substance use and mental health correlates of nonadherence to antiretroviral medications in a sample of patients with human immunodeficiency virus infection. Am J Med. 2003; 114(7):573-80. [PubMed: 12753881]

3. Turner BJ, et al. Effects of drug abuse and mental disorders on use and type of antiretroviral therapy in HIV-infected persons. J Gen Intern Med. 2001; 16(9):625-33. [PubMed: 11556944]

4. Benton TD. Depression and HIV/AIDS. Curr Psychiatry Rep. 2008; 10(3):280-5. [PubMed: 18652798]

5. Bhatia R, et al. Persons newly diagnosed with HIV infection are at high risk for depression and poor linkage to care: results from the Steps Study. AIDS Behav. 2011; 15(6):1161-70. [PubMed: 20711651]

6. Tobias CR, et al. Living with HIV but without medical care: barriers to engagement. AIDS Patient Care STDS. 2007; 21(6):426-34. [PubMed: 17594252]

7. Gonzalez JS, et al. Depression and HIV/AIDS treatment nonadherence: a review and meta-analysis. J Acquir Immune Defic Syndr. 2011; 58(2):181-7. [PubMed: 21857529]

8. Pence BW, O'Donnell JK, Gaynes BN. Falling through the cracks: the gaps between depression prevalence, diagnosis, treatment, and response in HIV care. AIDS. 2012; 26(5):656-8. [PubMed: 22398574]

9. Pence BW, et al. Psychiatric illness and virologic response in patients initiating highly active antiretroviral therapy. J Acquir Immune Defic Syndr. 2007; 44(2):159-66. [PubMed: 17146374]

10. Leserman J. Role of depression, stress, and trauma in HIV disease progression. Psychosom Med. 2008; 70(5):539-45. [PubMed: 18519880]

11. Angelino AF, Treisman GJ. Management of psychiatric disorders in patients infected with human immunodeficiency virus. Clin Infect Dis. 2001; 33(6):847-56. [PubMed: 11512090]

12. Tsai AC, et al. Directly observed antidepressant medication treatment and HIV outcomes among homeless and marginally housed HIV-positive adults: a randomized controlled trial. Am J Public Health. 2013; 103(2):308-15. [PubMed: 22720766]

13. Tsai AC, et al. A marginal structural model to estimate the causal effect of antidepressant medication treatment on viral suppression among homeless and marginally housed persons with HIV. Arch Gen Psychiatry. 2010; 67(12):1282-90. [PubMed: 21135328] 
14. Sin NL, Dimatteo MR. Depression Treatment Enhances Adherence to Antiretroviral Therapy: a Meta-Analysis. Ann Behav Med. 2013

15. Safren SA, et al. A randomized controlled trial of cognitive behavioral therapy for adherence and depression (CBT-AD) in HIV-infected individuals. Health Psychol. 2009; 28(1):1-10. [PubMed: 19210012]

16. Pyne JM, et al. Effectiveness of collaborative care for depression in human immunodeficiency virus clinics. Arch Intern Med. 2011; 171(1):23-31. [PubMed: 21220657]

17. Gross R, et al. Managed problem solving for antiretroviral therapy adherence: a randomized trial. JAMA Intern Med. 2013; 173(4):300-6. [PubMed: 23358784]

18. Gross R, et al. The effects of a problem solving-based intervention on depressive symptoms and HIV medication adherence are independent. PLoS One. 2014; 9(1):e84952. [PubMed: 24400124]

19. Kessler RC, et al. Prevalence, severity, and comorbidity of 12-month DSM-IV disorders in the National Comorbidity Survey Replication. Arch Gen Psychiatry. 2005; 62(6):617-27. [PubMed: 15939839]

20. Kessler RC, et al. Prevalence, Severity, and Comorbidity of 12-Month DSM-IV Disorders in the National Comorbidity Survey Replication. Arch Gen Psychiatry. 2005; 62(6):617-627. [PubMed: 15939839]

21. Barroso J, et al. Physiological and psychosocial factors that predict HIV-related fatigue. AIDS Behav. 2010; 14(6):1415-27. [PubMed: 20352317]

22. Hirschfeld RM. The Comorbidity of Major Depression and Anxiety Disorders: Recognition and Management in Primary Care. Prim Care Companion J Clin Psychiatry. 2001; 3(6):244-254. [PubMed: 15014592]

23. Katon W, Lin EH, Kroenke K. The association of depression and anxiety with medical symptom burden in patients with chronic medical illness. Gen Hosp Psychiatry. 2007; 29(2):147-55. [PubMed: 17336664]

24. Sherbourne CD, et al. Comorbid anxiety disorder and the functioning and well-being of chronically ill patients of general medical providers. Arch Gen Psychiatry. 1996; 53(10):889-95. [PubMed: 8857865]

25. Riley ED, et al. Basic subsistence needs and overall health among human immunodeficiency virusinfected homeless and unstably housed women. Am J Epidemiol. 2011; 174(5):515-22. [PubMed: 21749972]

26. Riley ED, et al. Recent violence in a community-based sample of homeless and unstably housed women with high levels of psychiatric comorbidity. Am J Public Health. 2014; 104(9):1657-63. [PubMed: 25033127]

27. Pence BW, et al. Assessing the effect of Measurement-Based Care depression treatment on HIV medication adherence and health outcomes: rationale and design of the SLAM DUNC Study. Contemp Clin Trials. 2012; 33(4):828-38. [PubMed: 22542960]

28. Kroenke K, Spitzer RL, Williams JB. The PHQ-9: validity of a brief depression severity measure. Journal of General Internal Medicine. 2001; 16(9):606-13. [PubMed: 11556941]

29. Lecrubier Y, et al. The MINI International Neuropsychiatric Interview (M.I.N.I.) A Short Diagnostic Structured Interview: Reliability and Validity According to the CIDI. European Psychiatry. 1997; 12:224-231.

30. Lecrubier Y, et al. The Mini International Neuropsychiatric Interview (MINI). A short diagnostic structured interview: Reliability and validity according to the CIDI. European Psychiatry. 1997; 12(5):224-231.

31. Sheehan DV, et al. The validity of the Mini International Neuropsychiatric Interview (MINI) according to the SCID-P and its reliability. European Psychiatry. 1997; 12(5):232-241.

32. American Psychiatric Association. Diagnostic and Statistical Manual of Mental Disorders. 4th (text revision) ed.. Washington, DC.: 2000.

33. American Psychiatric Association. Diagnostic and Statistical Manual of Mental Disorders. American Psychiatric Publishing; Arlington, VA.: 2013.

34. Amico KR, et al. Visual analog scale of ART adherence: association with 3-day self-report and adherence barriers. J Acquir Immune Defic Syndr. 2006; 42(4):455-9. [PubMed: 16810111] 
35. Bing EG, et al. Psychiatric disorders and drug use among human immunodeficiency virus-infected adults in the United States. Arch Gen Psychiatry. 2001; 58(8):721-8. [PubMed: 11483137]

36. Ware J, Kosinski M, Keller S. A 12-item Short-form Health Survey: construction of scales and preliminary tests of reliability and validity. Medical Care. 1996; 32:220-233. [PubMed: 8628042]

37. Hamilton M. A rating scale for depression. J Neurol Neurosurg Psychiatry. 1960; 23:56-61. [PubMed: 14399272]

38. Gureje O. Dysthymia in a cross-cultural perspective. Curr Opin Psychiatry. 2011; 24(1):67-71. [PubMed: 21088583]

39. Tegger MK, et al. The effect of mental illness, substance use, and treatment for depression on the initiation of highly active antiretroviral therapy among HIV-infected individuals. AIDS Patient Care STDS. 2008; 22(3):233-43. [PubMed: 18290749]

40. Israelski DM, et al. Psychiatric co-morbidity in vulnerable populations receiving primary care for HIV/AIDS. AIDS Care. 2007; 19(2):220-5. [PubMed: 17364402]

41. Orlando M, et al. Brief screening of psychiatric disorders among a national sample of HIV-positive adults: Concordance between the Composite International Diagnostic Interview (CIDI) and the CIDI Short Form (CIDI-SF). Int J Methods Psychiatr Res. 2001; 10:97-107.

42. Orlando M, et al. Re-estimating the prevalence of psychiatric disorders in a nationally representative sample of persons receiving care for HIV: results from the HIV Cost and Services Utilization Study. Int J Methods Psychiatr Res. 2002; 11(2):75-82. [PubMed: 12459797]

43. Schumacher JE, et al. Routine Depression Screening in an HIV Clinic Cohort Identifies Patients with Complex Psychiatric Co-morbidities Who Show Significant Response to Treatment. AIDS Behav. 2013; 17(8):2781-91. [PubMed: 23086427] 


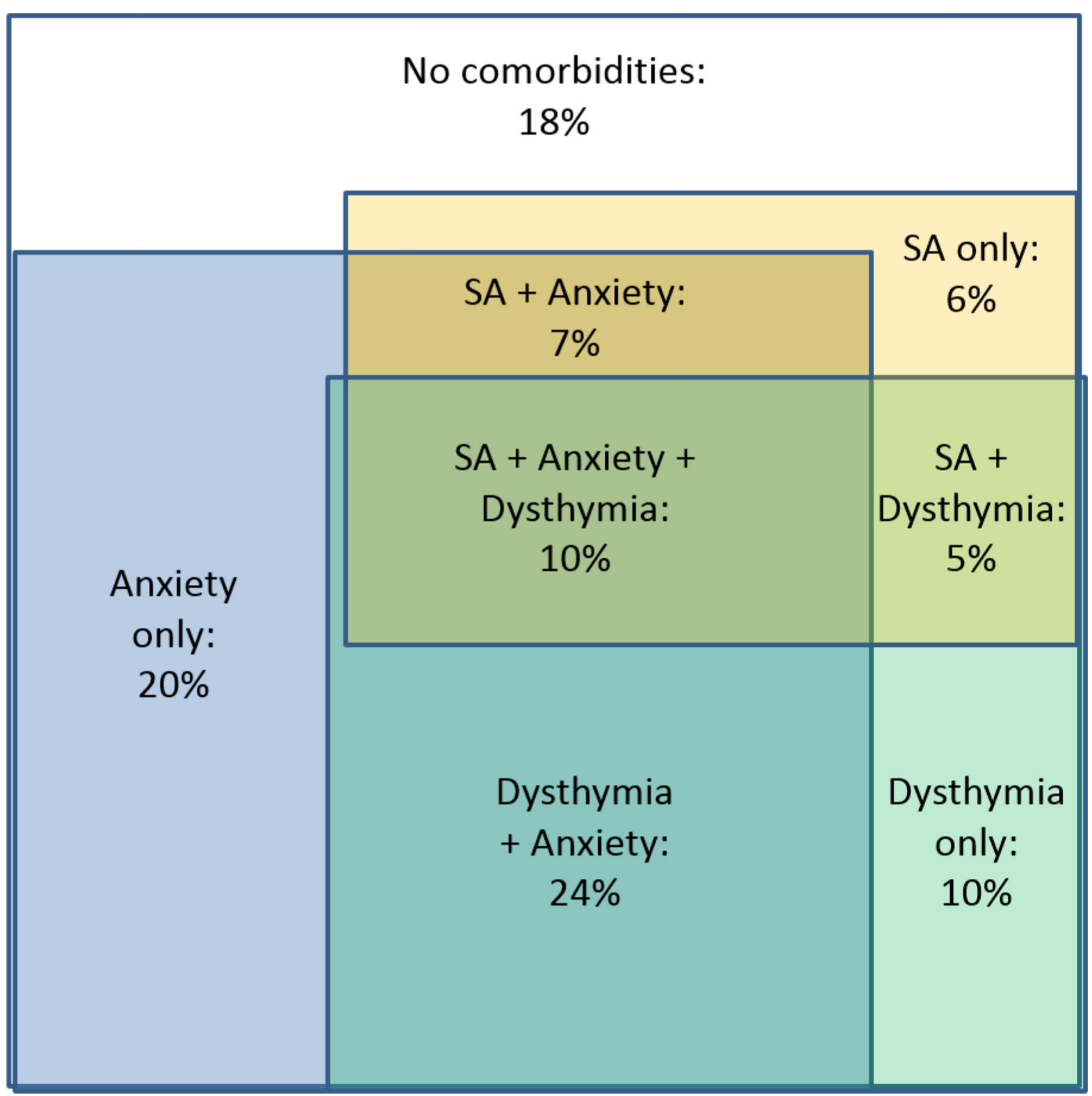

Figure 1.

Psychiatric comorbidities among HIV-infected people with major depression. 


\section{Table 1}

Description of sample $(n=304)$.

\begin{tabular}{|c|c|}
\hline Characteristic & Mean (SD) or n (\%) \\
\hline$\underline{\text { Sociodemoaraphic Measures }}$ & - \\
\hline Age, years & $44(10)$ \\
\hline \multicolumn{2}{|l|}{ Sex } \\
\hline Male & $215(71 \%)$ \\
\hline Female & $89(29 \%)$ \\
\hline \multicolumn{2}{|l|}{ Race } \\
\hline White non-Hispanic & $93(31 \%)$ \\
\hline Black non-Hispanic & $188(62 \%)$ \\
\hline Hispanic & $9(3 \%)$ \\
\hline Other & $14(5 \%)$ \\
\hline Income (monthly), \$ & $\$ 1,534(2,887)$ \\
\hline \multicolumn{2}{|l|}{ Marital Status } \\
\hline Married/co-habitating & $68(23 \%)$ \\
\hline Separated, divorced, widowed & $78(26 \%)$ \\
\hline Single/never married & $155(51 \%)$ \\
\hline \multicolumn{2}{|l|}{ Employment Status } \\
\hline Employed & $81(27 \%)$ \\
\hline Unemployed & $219(73 \%)$ \\
\hline Time since diagnosis (years) & $11(8)$ \\
\hline Education (years completed) & $13(3)$ \\
\hline \multicolumn{2}{|l|}{ Past depressive episodes } \\
\hline None & $124(41 \%)$ \\
\hline$\geq 1$ & $180(59 \%)$ \\
\hline Behavioral and Health Measures & - \\
\hline Self-reported adherence, past month & $87(23)$ \\
\hline Number HIV symptoms, past 6 months & $5.1(3.0)$ \\
\hline SF-12 mental functioning & $30(10)$ \\
\hline SF-12 physical functioning & $44(12)$ \\
\hline HIV RNA VL >48 copies/mL & $101(33 \%)$ \\
\hline Any unprotected sex, past 3 months & $56(18 \%)$ \\
\hline Any unprotected sex with HIV- or status-unknown partner & $25(8 \%)$ \\
\hline Any suicidality, past week & $91(30 \%)$ \\
\hline Any hospitalization, past 3 months & $20(7 \%)$ \\
\hline Any emergency department visit, past 3 months & $74(25 \%)$ \\
\hline
\end{tabular}




\section{Table 2}

Prevalence of psychiatric comorbidities at baseline among SLAM DUNC study participants.

\begin{tabular}{lcc}
\hline Diagnosis & $\mathbf{n}$ & $\mathbf{\%}$ \\
\hline Dysthymia & 148 & $49 \%$ \\
Any anxiety disorder & 187 & $62 \%$ \\
$\quad$ Panic disorder, current & 43 & $14 \%$ \\
$\quad$ PTSD, current & 65 & $22 \%$ \\
$\quad$ GAD & 144 & $48 \%$ \\
Any substance use disorder & 85 & $28 \%$ \\
$\quad$ Alcohol abuse (no dependence) & 14 & $5 \%$ \\
$\quad$ Alcohol dependence & 44 & $15 \%$ \\
$\quad$ Drug abuse (no dependence) & 8 & $3 \%$ \\
$\quad$ Drug dependence & 47 & $16 \%$ \\
Number of comorbid diagnoses & & \\
0 & 54 & $18 \%$ \\
$\mathbf{1}$ & 90 & $30 \%$ \\
$\mathbf{2}$ & 85 & $28 \%$ \\
$\mathbf{3}$ or more & 75 & $25 \%$ \\
\hline
\end{tabular}

In addition to MDD 
Table 3

Demographic, behavioral, and health correlates of comorbidity

\begin{tabular}{|c|c|c|c|c|c|c|c|c|}
\hline & \multicolumn{3}{|c|}{ Number of comorbidities } & \multicolumn{5}{|l|}{ Type of comorbidity* } \\
\hline & None & 1 or more & P Value & None or dysthymia & $\begin{array}{l}\text { Anxiety } \\
\text { but no SA }\end{array}$ & P value ${ }^{*}$ & Substance use & P Value ${ }^{* * * *}$ \\
\hline $\mathbf{n}$ & $54(18 \%)$ & $250(82 \%)$ & & $83(27 \%)$ & $136(45 \%)$ & & $85(28 \%)$ & \\
\hline Age, years & $44(11)$ & $44(10)$ & 0.84 & $44(11)$ & $45(9)$ & 0.44 & $43(11)$ & 0.55 \\
\hline \multicolumn{9}{|l|}{ Sex } \\
\hline Male & $35(65 \%)$ & $180(72 \%)$ & 0.29 & $59(71 \%)$ & $87(64 \%)$ & 0.28 & $69(81 \%)$ & 0.13 \\
\hline Female & $19(35 \%)$ & $70(28 \%)$ & & $24(29 \%)$ & $49(36 \%)$ & & $16(19 \%)$ & \\
\hline \multicolumn{9}{|l|}{ Race } \\
\hline White non-Hispanic & $12(22 \%)$ & $80(32 \%)$ & 0.24 & $21(25 \%)$ & $48(35 \%)$ & 0.05 & $24(28 \%)$ & 0.65 \\
\hline Black non-Hispanic & $38(70 \%)$ & $150(60 \%)$ & & $55(66 \%)$ & $81(60 \%)$ & & $52(61 \%)$ & \\
\hline Hispanic & $1(2 \%)$ & $12(5 \%)$ & & $2(2 \%)$ & $6(4 \%)$ & & $5(6 \%)$ & \\
\hline Other & $3(6 \%)$ & $7(3 \%)$ & & $5(6 \%)$ & $1(1 \%)$ & & $4(5 \%)$ & \\
\hline Income, $\log (10)$ & $2.7(1.1)$ & $2.7(1.0)$ & 0.98 & $2.7(1.1)$ & $2.7(1.0)$ & 0.97 & $2.7(1.0)$ & 0.89 \\
\hline \multicolumn{9}{|l|}{ Marital Status } \\
\hline Married/co-habitating & $10(19 \%)$ & $58(23 \%)$ & 0.73 & $16(19 \%)$ & $37(27 \%)$ & 0.28 & $15(18 \%)$ & 0.95 \\
\hline Separated, divorced, widowed & $15(28 \%)$ & $63(26 \%)$ & & $21(25 \%)$ & $37(27 \%)$ & & $20(24 \%)$ & \\
\hline Single/never married & $29(54 \%)$ & $126(51 \%)$ & & $46(55 \%)$ & $61(45 \%)$ & & $48(58 \%)$ & \\
\hline \multicolumn{9}{|l|}{ Employment Status } \\
\hline Employed & $21(41 \%)$ & $59(24 \%)$ & 0.01 & $31(38 \%)$ & $29(21 \%)$ & 0.01 & $21(25 \%)$ & 0.08 \\
\hline Unemployed & $32(59 \%)$ & $187(76 \%)$ & & $51(62 \%)$ & $106(79 \%)$ & & $62(75 \%)$ & \\
\hline Time since diagnosis (years) & $12(10)$ & $11(8)$ & 0.50 & $11(9)$ & $12(8)$ & 0.78 & $10(8)$ & 0.56 \\
\hline Education (years completed) & $14(4)$ & $13(2)$ & 0.48 & $13(4)$ & $13(2)$ & 0.83 & $13(3)$ & 0.42 \\
\hline $\begin{array}{l}\text { Self-reported adherence, past } \\
\text { month }\end{array}$ & $86 \%(24 \%)$ & $87 \%(22 \%)$ & 0.83 & $84 \%(27 \%)$ & $88 \%(21 \%)$ & 0.24 & $86 \%(19 \%)$ & 0.76 \\
\hline $\begin{array}{l}\text { Number of HIV symptoms, } \\
\text { past } 6 \text { months }\end{array}$ & $4.1(3.0)$ & $5.1(2.9)$ & 0.01 & $4.2(3.0)$ & $5.4(2.9)$ & 0.01 & $5.6(2.8)$ & 0.00 \\
\hline SF-12 MCS Score & $35(13)$ & $29(9)$ & 0.00 & $33(12)$ & $28(8)$ & 0.00 & $31(9)$ & 0.14 \\
\hline SF-12 PCS Score & $47(13)$ & $43(12)$ & 0.08 & $46(13)$ & $42(11)$ & 0.01 & $46(12)$ & 0.97 \\
\hline $\begin{array}{l}\text { Self-reported adherence } \\
>=80 \% \text {, past month }\end{array}$ & $41(84 \%)$ & $185(81 \%)$ & 0.68 & $64(82 \%)$ & $104(85 \%)$ & 0.64 & $48(76 \%)$ & 0.38 \\
\hline HIV RNA VL >48 copies $/ \mathrm{mL}$ & $16(31 \%)$ & $74(33 \%)$ & 0.85 & $23(31 \%)$ & $35(28 \%)$ & 0.69 & $32(42 \%)$ & 0.16 \\
\hline $\begin{array}{l}\text { Any unprotected sex, past } 3 \\
\text { months }\end{array}$ & $10(20 \%)$ & $46(21 \%)$ & 0.94 & $15(19 \%)$ & $21(17 \%)$ & 0.65 & $20(29 \%)$ & 0.16 \\
\hline $\begin{array}{l}\text { Any unprotected sex with } \\
\text { HIV-or status-unknown } \\
\text { partner }\end{array}$ & $5(10 \%)$ & $20(9 \%)$ & 0.81 & $7(9 \%)$ & $11(9 \%)$ & 0.96 & $7(10 \%)$ & 0.81 \\
\hline Any suicidality, past week & $12(24 \%)$ & $79(36 \%)$ & 0.10 & $22(28 \%)$ & $46(38 \%)$ & 0.17 & $23(34 \%)$ & 0.46 \\
\hline $\begin{array}{l}\text { Any hospitalization, past } 3 \\
\text { months }\end{array}$ & $3(6 \%)$ & $17(7 \%)$ & 0.72 & $3(4 \%)$ & $10(7 \%)$ & 0.25 & $7(9 \%)$ & 0.19 \\
\hline $\begin{array}{l}\text { Any emergency department } \\
\text { visit, past } 3 \text { months }\end{array}$ & $13(24 \%)$ & $61(25 \%)$ & 0.91 & $23(28 \%)$ & $35(26 \%)$ & 0.77 & $16(20 \%)$ & 0.22 \\
\hline
\end{tabular}

Gen Hosp Psychiatry. Author manuscript; available in PMC 2016 July 01. 
* P value comparing None or dysthymia to Anxiety but no SA

*** P value comparing None or dysthymia to Substance use 


\section{Table 4}

Independent associations of dysthymia, anxiety, and substance use comorbidity with HIV behavioral and health outcomes

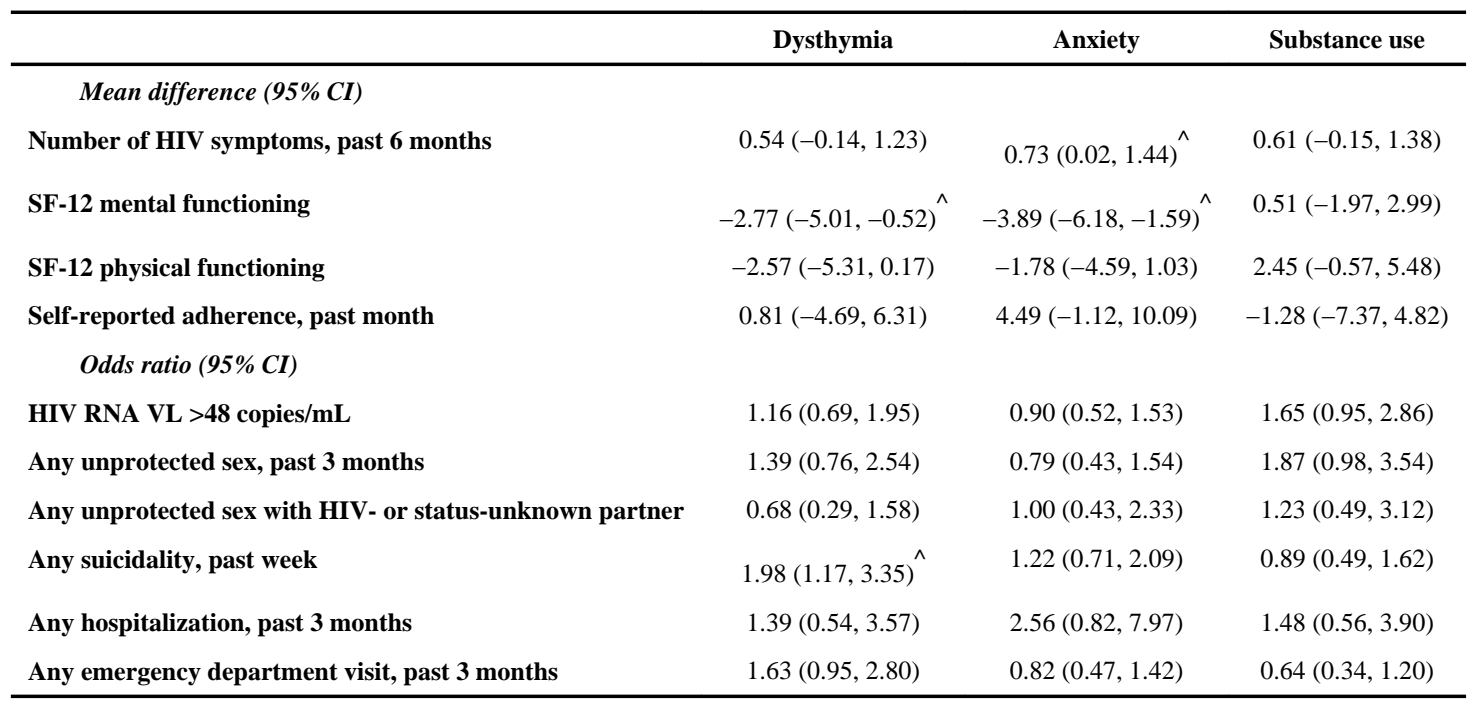

* From ordinary least squares or logistic regression models, adjusted for age, gender, and employment status. $\hat{\mathrm{p}}<0.05$ 